\title{
Role of local government in responding to environmental health challenges: a case study of Chungnam
}

\author{
Hyung-Nam Myung ${ }^{1}$, Hoo-Young Lee ${ }^{2}$ \\ ${ }^{1}$ Department of Environment and Ecology Research, ChungNam Institute, Gongju, Korea; ${ }^{2}$ Department of Environmental \\ Health, Chungnam Provincial Government, Hongseong, Korea
}

The purpose of this study is to introduce the establishment process, policy target, and projects for "Chungnam's master plan on environmental health policy (2017-2020)" as the local government's role in addressing local environmental health challenges. We first analyzed existing studies and social issues on the media related to "Chungnam's master plan" to understand Chungnam's environmental health status and discussed domestic and international policy trends and related plans. An environmental health perception questionnaire survey and a Delphi expert questionnaire survey were conducted among provincial residents to collect various actors' opinions on Chungnam's environmental health issues and policy. An expert advisory panel was launched, and a residents' voice workshop and cities-and-guns-policy-suggestion workshop were held. The vision of Chungnam's environmental health policy is minimizing environmental hazards. We finally selected "Pleasant environment, healthy people, happy Chungnam" to represent the will to shape a pleasant environment and prevent and manage health damages for a happy Chungnam. We selected five strategies based on status analysis and a review of domestic and international policy trends and related plans and identified 2 targets (policy objectives) to accomplish the strategies. The strategies to achieve the first target, "Leader in environmental health policy: Chungnam," include "Empowering active provincial capabilities,' 'Setting up province-specific systems for environmental health surveys and research,' and 'Preventing and managing newly emerging pollutants.' The strategies for the second target, "Everyone is healthy: Chungnam," include 'Relieving health inequalities among vulnerable regions and residents' and 'Enlarging the resident-friendly environmental health policy.' We developed 29 projects in total, according to these strategies. The establishment of "Chungnam's master plan" is highly valuable; we developed it through discussion involving diverse actors to address environmental health challenges together. It is necessary to continue to strengthen participation, communication, and cooperation among actors to develop an environmental health policy model for the future.

Keywords Environmental health, Local government, Policy, Chungnam, Korea
Correspondence: Hyung-Nam Myung Department of Environment and Ecology Research, ChungNam Institute, 73-26 Yeonsuwon-gil, Gongju 32589, Korea E-mail: myunghn@gmail.com

Received: June 20, 2017 Accepted: November 24, 2017 Published: November 24, 2017

This article is available from: http://e-eht.org/

\section{INTRODUCTION}

The Ministry of Environment enacted the "Environmental Health Act" in 2008 as a measure to implement receptor-orient- ed integrated management in response to the growing demand for environmental health policy. The Ministry of Environment established and currently implements the "Central government environmental health master plan" as a plan to protect public 
health. Unfortunately, concerns and criticism continue to rise because the current environmental health policy is led by the central government and environmental health experts. The plan does not properly address the real demands of environmental health. The necessity of establishing an environmental health policy that reflected local characteristics arose to overcome this challenge, and the competence and role of the local government are being further stressed [1].

Chungnam is home to various cities and farming villages, and there are several emerging environmental health challenges because of its geological characteristics. After the establishment of large-scale industrial complexes in the 1990s, the province did experience positive effects such as regional development. However, environmental health concerns and negative factors for safety and health are arising at the same time. It is noteworthy that $48 \%$ of the nation's coal thermal power is generated in Chungnam for reasons such as the facility for coal import and the proximity to metropolition area. Residents' concerns about health damages are increasing as a result of incidents involving transmission towers, steel and petrochemical complexes, asbestos mines, metal mines, oil spills, and chemical accidents such as hydrofluoric acid spills.

In order to address these local challenges, the province of Chungnam declared the 'Environmental Health Charter' in 2012. It became the first province to establish "Chungnam's master plan on environmental health policy (2012-2016)” among the local governments of Korea. In 2014, it legislated the Environmental Health Ordinance and created an Environmental Health Team. In 2017, Chungnam established "Chungnam's second master plan on environmental health policy (20172020)" to ensure its consistency with the central government's environmental health policy and reflect the changes in the environment and its provincial characteristics [2].

The purpose of this study is to analyze the environmental health status of Chungnam in this context and to suggest a detailed establishment process, policy targets, and projects for "Chungnam's master plan on environmental health policy (2017-2020)” as the local government's role in addressing local environmental health challenges.

\section{METHODS}

\section{Analysis of Environmental Health Status and Issues}

Figure 1 shows the study method and the structure of Chungnam's master plan on environmental health policy. We reviewed existing studies including reports and papers and collected and analyzed statistical data on the central government and Chungnam. We collected issues treated in the media over the last 3 years (from 2014 to 2016) and categorized them to analyze the environmental health issues of 15 cities and guns.

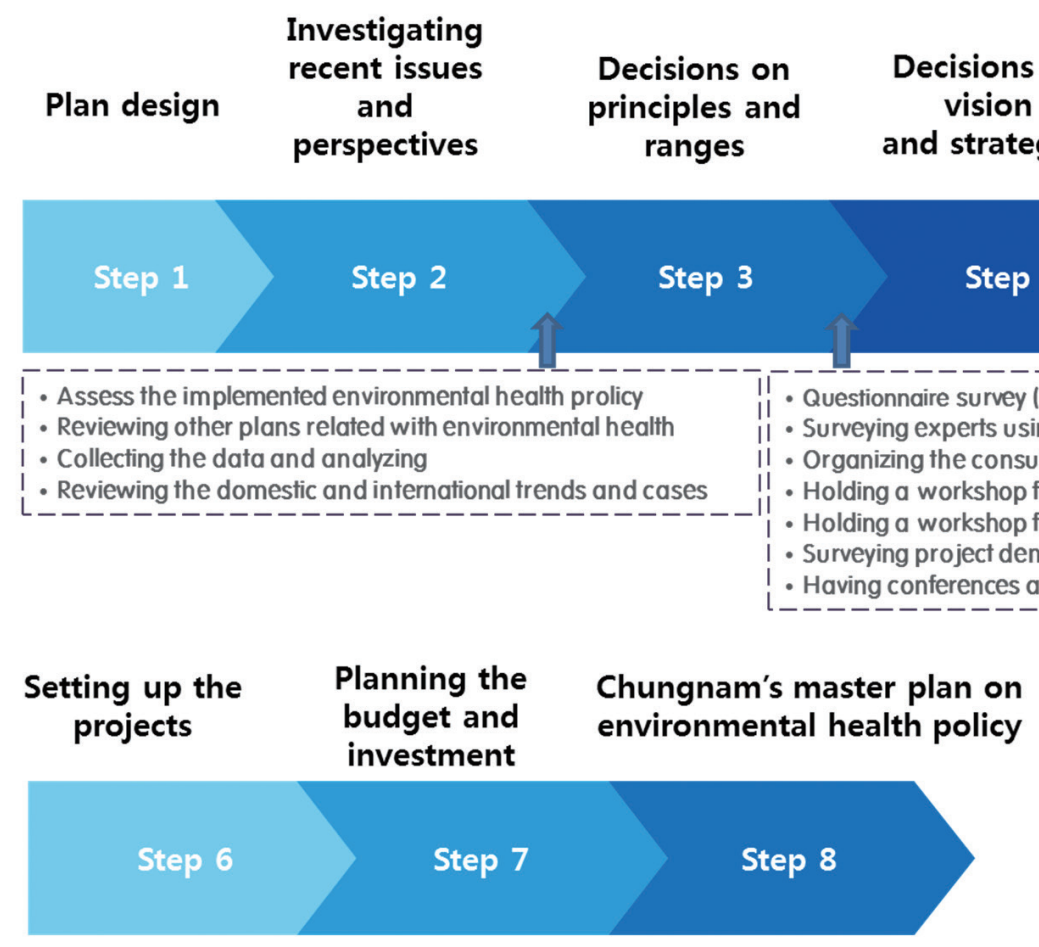

Figure 1. Process of implementing Chungnam's master plan on environmental health policy. 
Reviewing Domestic and Overseas Policy Trends and Drawing Implications

We reviewed the "Central government environmental master plan (2016-2035)," the "Central government environmental health master plan (2011-2020: to be modified)," and the "Child environmental health master plan (2013-2017)" as plans related to the central government [3-5]. As for plans related to Chungcheongnam-do (Chungnam), "Chungnam's master plan on environmental conservation policy (2016-2025)" was reviewed [6]. We reviewed the World Health Organizaion (WHO)'s National Environmental Health Action Plans, European Environmental Health Action Plan, and the American Community Action for a Renewed Environment for international environmental health policy trends [7-9]. After the review of plans related to the central government and Chungnam and the analysis of domestic and international policy trends, we drew six final key implications that can be applied to Chungnam.

\section{Ascertaining the Opinions of Various Actors}

We ascertained the opinions of various actors to establish "Chungnam's master plan on environmental health policy (2017-2020)" more effectively. The provincial residents environmental health perception questionnaire survey was conducted with 550 residents living in the Chungnam province aged over 18 through face-to-face interviews from September 27 to October 10, 2016. The number of citizens from each of the 15 cities and guns was assigned in proportion to their populations to select a sample representing the province's population. The Delphi expert questionnaire survey was conducted with 28 regional experts knowledgeable about Chungnam's environmental health status. The open question survey was conducted in stage 1 of the Delphi method. In stage 2, the results of the stage 1 questions were analyzed and the subjects were asked to respond to the questionnaire again. In stage 3 , subjects were informed of the survey results of stage 2 so that they could refer to others' responses. They were instructed to respond to additional questions to balance their opinion $[1,10]$.

The expert advisory consisted of 23 experts from the private and public sectors, industry, academia, and research field. Expert meetings were held four times, and a project demand survey was carried out to collect opinions on the direction of and projects for the environmental health master plan. The residents voice workshop was carried out with residents living in the province of Chungnam to help them directly participate in the process of discovering environmental health issues and establishing the policy. Chungnam was divided into 4 areas and the workshop was held once in each area with about 30 residents and representatives from local non-governmental organizations, four times in total. The cities and guns policy suggestion workshop was held once with 15 public officers of environmental service and 30 employees at community health centers in the 15 cities and guns to hear their complaints concerning the community's environmental health issues and survey their policy suggestions.

\section{RESULTS}

\section{Analysis of Environmental Health Status and Issues}

Chungnam is a province with the highest risk of exposure to naturally occurring asbestos in Korea. For this reason, 46.0 and $36.6 \%$ of patients with asbestos-related diseases in Chungnam live in the city of Boryeong and the Hongseong-gun, which multiple asbestos mines. The north-west area where coal thermal power plants and petrochemical and steel complexes are concentrated emits more than $90 \%$ of the air pollutants in the Chungnam province. A survey on public health in the northwestern area conducted from 2013 through 2015 revealed that the geometric mean of blood cadmium in residents living in areas exposed to the steel and petrochemical complexes was 1.40 and $1.84 \mu \mathrm{g} / \mathrm{L}$, respectively, which was noticeably higher than the $1.13 \mu \mathrm{g} / \mathrm{L}$ in inland areas. The geometric mean of total urinary arsenic was $181.47 \mu \mathrm{g} / \mathrm{g}$ cr in the areas exposed to steel complexes, which was approximately twice as high as that of other cities $(88.75 \mu \mathrm{g} / \mathrm{g} \mathrm{cr})[11]$. The results of a survey on public health in areas adjacent to the former Janghang smelter conducted from 2008 to 2010 showed that 165 residents (24.0\%) out of 687 exceeded the maximum cadmium exposure rate recommended by the WHO. A follow-up project was conducted until 2016 as a result of the high exposure rates. A survey on public health in Taean County was conducted since 2009 after the Hebei Spirit oil spill. Its results revealed that, even though the symptoms observed during the acute phase disappeared, risk factors for chronic diseases were observed in the high-exposure resident group. Thus mid-term and long-term monitoring is conducted on the subjects. According to analysis of the National Health Insurance Service's health insurance claim data (2004-2013), the annual average of patients with asthma was 4174 per 100000 , which took the 10th place in the national ranking. However, the number is rapidly increasing and the northwest area of Chungnam shows a particularly high rate of prevalence. In respect to radon, which causes lung cancer, the average rate of radon in housing in winter was fourth highest in Korea in 2014 due to Chungnam's geological characteristics. 


\section{Domestic and International Policy Trend Review and Implications}

The key implications applicable to Chungnam, which we finalized through analysis of plans related to domestic and international policy trends, included strengthening community-led environmental health capacity, scientifically investigating health damages in the community, implementing prevention policy to address newly emerging environmental hazards, applying an environmental health policy reflecting residents' needs, strengthening programs for children, and establishing a cooperation system to work with organizations related to environment and health.

\section{Collecting Opinions of Various Actors}

The gender ratio of respondents of the provincial residents' environmental health perception questionnaire survey was balanced as women accounted for $270(49.0 \%)$ out of a total of 550 respondents. In terms of age, 92 (16.6\%) were aged 20-29, 129 (23.5\%); 30-39, 139 (25.3\%); 40-49, 106 (19.3\%); 50-59, and $84(15.3 \%)$ over 60 , with those in their 40 s being the majority. In the Delphi expert questionnaire survey with 28 experts, 2 (7.2\%) were aged 30-39, 13 (46.4\%); 40-49, and 13
(46.4\%); 50-59. Respondents work experience in current position by year showed that 21 experts have been working for more than 10 years $(75.0 \%)$.

The results of the provincial residents environmental health perception questionnaire survey and the Delphi expert questionnaire survey revealed that there was a perception gap between the two groups (Table 1). Residents named climate change (3.85), air pollution (3.73), electromagnetic waves (3.59) in order to answer a 5-point scale question asking about the gravity of each environmental factor affecting health. However, the expert group responded in the order of air pollution (3.58), hazardous chemicals (3.54), and asbestos (3.50). This indicates that residents' perception of the gravity of environmental factors affecting health was slightly higher than experts. With regard to the priorities in the environmental health policy, residents' most frequent answers were enlarging the resident-friendly environmental health policy (38.7\%). Contrarily, experts mostly chose policy for vulnerable regions and residents (39.3\%).

As for the biggest challenges in developing the environmental health policy, residents chose distrust of administrative authorities (28.0\%). Conversely, most of the expert group responded

Table 1. Results of questionnaire survey on environmental health perceptions (residents of Chungnam \& experts)

\begin{tabular}{|c|c|c|c|}
\hline Questions & Items & Residents of Chungnam & Experts \\
\hline \multirow{10}{*}{$\begin{array}{l}\text { The level of health effect from } \\
\text { environmental factors ( } 5 \text { point scale) })^{\text {a }}\end{array}$} & Climate change & 3.85 & 2.96 \\
\hline & Air pollution & 3.73 & 3.58 \\
\hline & Electromagnetic waves & 3.59 & 2.73 \\
\hline & Hazardous chemicals & 3.59 & 3.54 \\
\hline & Soil pollution & 3.56 & 2.88 \\
\hline & Water pollution & 3.50 & 3.27 \\
\hline & Noise vibration & 3.39 & 2.96 \\
\hline & Asbestos & 3.33 & 3.50 \\
\hline & Indoor radiation & 3.24 & 2.54 \\
\hline & Artificial light & 3.20 & 2.27 \\
\hline \multirow{9}{*}{$\begin{array}{l}\text { The most urgent issue to be } \\
\text { addressed ( } 5 \text { point scale) })^{\mathrm{a}}\end{array}$} & Air pollutants from coal-fired thermal power plant & 3.78 & 4.00 \\
\hline & Electromagnetic waves (a transmission tower) & 3.76 & 3.21 \\
\hline & Air pollutants from large industrial facilities & 3.73 & 3.93 \\
\hline & Odor from livestock excretions & 3.66 & 3.21 \\
\hline & Pollutants from small industries & 3.64 & 3.18 \\
\hline & Inappropriate incineration & 3.61 & 3.07 \\
\hline & Health problems due to spills of oily substances & 3.61 & 2.75 \\
\hline & Prevention and management of radon & 3.58 & 2.30 \\
\hline & Safety management for exposure to asbestos & 3.57 & 3.36 \\
\hline \multirow{5}{*}{$\begin{array}{l}\text { The priority of environmental } \\
\text { health policy }(n, \%)\end{array}$} & Enlarging the resident-friendly environmental health policy & $213(38.7)$ & $6(21.4)$ \\
\hline & Policy for newly emerging pollutants & $139(25.2)$ & $3(10.7)$ \\
\hline & Establishing a foothold for environmental health policy & $123(22.5)$ & 8 (28.6) \\
\hline & Policy for vulnerable regions and residents & $75(13.6)$ & $11(39.3)$ \\
\hline & Total & $550(100.0)$ & $28(100.0)$ \\
\hline \multirow{7}{*}{$\begin{array}{l}\text { The biggest challenges in developing the } \\
\text { environmental health policy }(n, \%)\end{array}$} & Distrust of administrative authorities & $154(28.0)$ & $1(3.6)$ \\
\hline & Lack of will to perform the environmental health policy & $117(21.3)$ & $2(7.1)$ \\
\hline & Residents'lack of understanding of the administration & $101(18.4)$ & $3(10.7)$ \\
\hline & Lack of adequate finance & $89(16.1)$ & $9(32.2)$ \\
\hline & Lack of professional manpower & $55(10.0)$ & $7(25.0)$ \\
\hline & Inefficiency in role sharing & $34(6.2)$ & $6(21.4)$ \\
\hline & Total & $550(100.0)$ & $28(100.0)$ \\
\hline
\end{tabular}

${ }^{a} 1$, rare; 2 , little; 3, mild; 4, moderate; 5 , severe. 
with lack of adequate finance (32.2\%). Residents and the expert group all named air pollutants from coal-fired thermal power plant as the most urgent issue to be addressed.

Based on the project demand survey with the expert advisory, we included conducting an open forum on environmental health, developing and applying Chungnam-specific environmental health indicators, health surveys for children living near coal-fired thermal power plants, a pilot study simulating an environmental health living lab attracting voluntary participation of residents, investigating the exposure pathway to heavy metals, managing the quality of ambient air and hazard risks in school areas and epidemiological investigation near transmission towers as new projects.

In the residents' voice workshop, residents suggested measures for asbestos safety management, and using resident-health-related big data as environmental health issues that need to be addressed by policy. In the 'cities and guns policy suggestion work- shop, an environmental disease' project based on the cooperation between environment and health departments was suggested for environmental health policy implementation.

\section{Direction of Environmental Health Policy}

We selected "pleasant environment, healthy people, happy Chungnam" as the vision of Chungnams environmental health policy, which was the most favored response in the residents' environmental health perception questionnaire survey. We suggested five strategies based on the six key points derived from the review of domestic and international policy trends and related plans. We then drew two targets (policy objectives) to realize the strategies. More specifically, we selected empowering active provincial capabilities, setting up province-specific systems for environmental health survey and research, and preventing and managing newly emerging pollutants as strategies to achieve the target, Leader in environmental health policy: Chungnam. As for strate-

Table 2. Results of Chungnam government's environmental health policy projects

\begin{tabular}{|c|c|c|c|}
\hline Targets & Strategies & Projects & Progression \\
\hline \multirow[t]{8}{*}{$\begin{array}{l}\text { Leader in environmental } \\
\text { health policy }\end{array}$} & Empowering active provincial capabilities & $\begin{array}{l}\text { Conducting an open forum on environmental health } \\
\text { Promoting personnel training } \\
\text { Increasing education programs for environmental health }\end{array}$ & $\begin{array}{l}\text { Supplementary } \\
\text { Supplementary } \\
\text { Not commenced }\end{array}$ \\
\hline & \multirow{2}{*}{$\begin{array}{l}\text { Setting up province-specific systems for } \\
\text { environmental health survey and research }\end{array}$} & $\begin{array}{l}\text { Establishing an information system for environmental health specific to } \\
\text { Chungnam }\end{array}$ & New \\
\hline & & Developing and applying Chungnam-specific environmental health indicators & New \\
\hline & \multirow{5}{*}{$\begin{array}{l}\text { Preventing and managing newly emerging } \\
\text { pollutants }\end{array}$} & Preventing and managing the adverse effects on health from artificial light & New \\
\hline & & $\begin{array}{l}\text { Preventing and managing the adverse effects on health from naturally } \\
\text { occurring asbestos }\end{array}$ & New \\
\hline & & Preventing and managing the adverse effects on health from radon & New \\
\hline & & Developing and operating the Honey Health Program for children & New \\
\hline & & $\begin{array}{l}\text { Preventing diseases related to environmental factors in the vulnerable } \\
\text { members of the population }\end{array}$ & Supplementary \\
\hline \multirow[t]{19}{*}{ Everyone is healthy } & \multirow{8}{*}{$\begin{array}{l}\text { Relieving health inequalities among } \\
\text { vulnerable regions and residents }\end{array}$} & Health survey for children living near coal-fired thermal power plants & New \\
\hline & & Investigating the ways in which residents are exposed to harmful heavy & New \\
\hline & & Managing the quality of ambient air and hazard risks in school areas & New \\
\hline & & Epidemiological investigation near transmission towers & New \\
\hline & & Health survey for residents living near coal-fired thermal power plants & Supplementary \\
\hline & & $\begin{array}{l}\text { Health survey for residents living in the Taean area polluted by spills of oily } \\
\text { substances }\end{array}$ & Supplementary \\
\hline & & $\begin{array}{l}\text { Health survey for residents living in areas susceptible to environmental } \\
\text { pollution }\end{array}$ & Existing \\
\hline & & Post health management of residents living near the Janghang ex-smelter & Existing \\
\hline & \multirow[t]{11}{*}{$\begin{array}{l}\text { Enlarging the resident-friendly } \\
\text { environmental health policy }\end{array}$} & $\begin{array}{l}\text { Pilot study simulating an environmental health living lab attracting } \\
\text { voluntary participation of residents }\end{array}$ & New \\
\hline & & Communicating environmental risks to villages & New \\
\hline & & Health care service to victims of asbestos exposure & New \\
\hline & & Measuring the quality of indoor air near thermal power plants & Existing \\
\hline & & $\begin{array}{l}\text { Measuring the quality of indoor air in facilities used by vulnerable members } \\
\text { of the population }\end{array}$ & Existing \\
\hline & & Managing indoor air in facilities with multiple users & Existing \\
\hline & & Managing environmental risks in facilities for children & Existing \\
\hline & & Offering a relief fund for victims of exposure to asbestos & Existing \\
\hline & & Consulting and measuring the quality of indoor air in nurseries & Existing \\
\hline & & Setting up a healing camp for patients exposed to asbestos & Existing \\
\hline & & Safety management of buildings generating asbestos & Existing \\
\hline
\end{tabular}


gies to achieve the target, Everyone is healthy: Chungnam, we selected relieving health inequalities among vulnerable regions and residents and enlarging the resident-friendly environmental health policy (Table 2).

\section{Chungnam's 29 Environmental Health Policy Projects}

Table 2 shows the 29 projects finally drawn according to Chungnam's environmental health policy targets (policy objectives) and 5 strategies. As for project selection, we reviewed all the central government's and Chungnam's projects currently in progress, the expert demand survey and residents' voice workshop, projects suggested at the cities and guns policy suggestion workshop, and those included in "Chungnam's master plan on environmental health policy (2012-2016)," which were not carried out. We grouped similar projects together and added some more projects where needed. As a result, we finally had a total of 29 projects consisting of 13 new projects, 5 supplementary projects, 10 existing projects, and 1 project that had not commenced, according to the strategies.

\section{Empowering Active Provincial Capabilities}

The community should be the ultimate actor that solves local environmental health challenges [9]. To this end, it is necessary to run a forum on environmental health, consisting of local public and private organizations, industries, universities, and research centers, as a place to discuss Chungnam's environmental health issues and alternatives and evaluate the performance of Chungnam's master plan on environmental health policy. It is also necessary to establish an organic network of administrative organizations and environmental health experts in cities and guns to implement an environmental health policy reflecting regional characteristics.

\section{Setting Up Province-specific Systems for Environmental Health Surveys and Research}

In order for Chungnam to establish a policy based on scientific evidence corresponding to the regional characteristics of Chungnam, it is necessary to establish a Chungnam-specific environmental health database to enhance the utility of related data resources. Therefore, it is necessary to establish an environmental health infrastructure in Chungnam that is comparable to the central government's environmental health levels. Further, environmental health indicators customized to the province should be developed to monitor changes in the environmental health status of the 15 cities and guns.

\section{Preventing and Managing Newly Emerging Pollutants}

Some areas of Chungnam, including farming villages and cit- ies, were turned into tourist places, and some cities and guns are receiving an increasing number of complaints from residents as a result of artificial lights during the nighttime. Health damage prevention and management measures should be implemented through ordinance enactment and the promotion of education. Chungnam is the province with the highest risk of exposure to naturally occurring asbestos owing to its geological characteristics. For this reason, a survey on asbestos health impacts should be conducted and preventing and managing should be carried out around the identified asbestos risk areas. Radon management plan will be established for cities and guns that record high indoor radon concentration in housing in cooperation with the central government. The Honey Health Program for children should be developed and operated in cooperation with the environmental disease prevention and care center, which is under construction in the city of Gongju, Chungnam.

\section{Relieving Health Inequalities Among Vulnerable Regions and Residents}

For the health survey among children living near coal-fired thermal power plants, a panel will be established for environmental exposure survey-monitoring and bio-monitoring of children's living environment. It is likely that large farming areas are highly polluted as many are concerned about heavy metals released from waste metals, asbestos mines, and coal thermal power plants. Therefore, this strategy includes an investigation project on exposure pathway to harmful heavy metals in order to identify harmful heavy metal exposure levels of residents and the sources of exposure to establish reduction measures. As for managing the quality of ambient air and hazard risks in school areas, air pollution in school zones will be monitored to identify the major causes. The project of epidemiological investigation near transmission towers is to carry out an epidemiological survey considering diseases and cancer prevalence related to transmission towers. Its objective is to establish measures for residents' health damage prevention and management in the surrounding areas.

\section{Enlarging the Resident-friendly Environmental Health Policy}

A pilot study simulating an environmental health living lab attracting voluntary participation of residents is a participatory survey and research project conducted together with residents to find solutions to the environmental health challenges perceived by residents. Communicating environmental risks to villages will produce a map showing the types of substances released from environmental facilities in villages, as well as the amounts released, health impacts, and evacuation methods and places in case of accidents. 
Health care service for victims of asbestos provides services in cooperation with local medical institutions. Nurses visit the homes of patients suffering from conditions caused by asbestos exposure to provide health checkups, education, and information on how to prevent the disease from worsening.

\section{DISCUSSION}

“Chungnam's master plan on environmental health policy (2017-2020)" is highly valuable because policies and projects required to solve regional environmental health challenges were developed through the participation of various local actors from private and public organizations, industries, academia, and research centers. It is expected that participation, communication, and cooperation between various actors will strengthen an environmental health policy model in the future [1].

With respect to the air pollution emitted from coal thermal power plants and health damage concerns in Chungnam, both residents and the expert group thought that it is a representative environmental health issue and should be addressed as being of the highest priority. We developed a health impact survey project concerning children and elderly people over 65 of age living in areas near coal thermal power plants and reflected on the opinions of residents and experts. The asbestos problem, which arises due to the geological characteristics of the province, is a risk factor for local communities and a major issue at the same time. For this reason, we developed the health care service for victims of asbestos, a healing camp, and preventing and managing the adverse effects on health from naturally occurring asbestos. Radon is a newly emerging community risk factor because of geological characteristics. We intend to minimize exposure by connecting with the radon pilot project conducted by the Ministry of Environment. Residents chose 'Enlarging the residentfriendly environmental health policy' most frequently as a toppriority environmental health policy area. We thus selected it as one of the strategies and assigned existing and new projects in order to implement a familiar environmental health policy that residents can experience and relate to better.

It is crucial to establish a system that regularly and systematically collects regional environmental health information in order to implement an environmental health policy reflecting regional characteristics. We developed Establishing an information system for environmental health specific to Chungnam, and the collected data are expected to be highly useful in establishing various future policies. The projects carried out in cooperation with the environment and health departments are Health care service for victims of asbestos exposure and Preventing diseases related to environmental factors.
The northern area of Chungnam is expected to experience an increasing health gap, owing to environmental pollution due to the distribution of a range of large-scale pollutant sources including coal thermal power plants, industrial (steel) and petrochemical complexes, waste metal mines, and livestock burial sites. In particular, the northern area is seeing an increasing number of vulnerable infants and young children (aged 0-9 years). We intend to clear the health gaps faced by vulnerable areas and groups by strengthening the health impact survey and monitoring these children.

Local governments continue to make great efforts to establish an environmental health policy that reflects local characteristics, not to mention the Gyeonggi-do Provincial Government and the Seoul Metropolitan Government, as well as Chungnam. The Seoul Metropolitan Government created an environmental health department in 2012 and enacted an environmental health ordinance. In 2013, it established the "Seoul Metropolitan Government's Environmental Health Policy Road Map (2013-2017)" to ensure continued and systematic implementation of environmental health policy [12]. The Gyeonggi-do Provincial Government established the "Strategies to achieve Atopy Free Gyeonggi-do” in 2011 [13]. As such cases continue to be implemented and accumulate at the local government lev$\mathrm{el}$, it will contribute to solving local environmental health challenges.

\section{ACKNOWLEDGEMENTS}

This study was supported by Chungcheongnam-do Provincial Government, Republic of Korea. We are grateful to all of the participating experts and officials involved in our study.

\section{CONFLICT OF INTEREST}

The authors have no conflicts of interest associated with the material presented in this paper.

\section{ORCID}

Hyung-Nam Myung http://orcid.org/0000-0003-0192-0522

\section{REFERENCES}

1. Myung HN, Yeo HB, Oh HJ. A study on environmental health policy in Chungnam. Gongju: ChungNam Institute; 2015, p. 1-2 (Korean).

2. Chungnam Provincial Government. Chungnam's master plan on environmental health policy (2017 2020). Hongseong: Chungnam Provincial Government; 2016, p. 5-6 (Korean). 
3. Ministry of Environment. Central government environmental master plan (2016-2035). Sejong: Ministry of Environment; 2016, p. 2-146 (Korean).

4. Ministry of Education; Ministry of Health and Welfare; Ministry of Environment. Central government environmental health master plan (2011-2020: to be modified). Sejong: Ministry of Environment; 2015, p. 2-143 (Korean).

5. Ministry of Environment. Child environmental health master plan (2013-2017). Gwacheon: Ministry of Environment; 2013, p. 2-52 (Korean).

6. Chungnam Provincial Government. Chungnam's master plan on environmental conservation policy (2016-2025). Hongseong: Chungnam Provincial Government; 2016, p. 309-340 (Korean).

7. World Health Organization. National Environmental Health Action Plans (NEHAPs); 2002 [cited 2017 Jun 15]. Available from: http://www.who.int/heli/impacts/nehaps/en/.

8. Health and Environment Alliance. The EU Environmental Health Action Plan (EHAP): assessment and outlook for future action;
2010 [cited 2017 Jun 15]. Available from: http://www.env-health. org/IMG/pdf/ehap_final_report_final.pdf.

9. US Environmental Protection Agency. Community Action for a Renewed Environment (CARE) resources; 2008 [cited 2017 Jun 17]. Available from: https://www.epa.gov/communityhealth/ community-action-renewed-environment-care-resources.

10. Vampini C, Gallelli L. A Delphi method-based survey of knowledge on their pharmacology and clinical use. Giornale Italiano di Psicopatologia 2014;20(3):322-340 (Italian).

11. Chungnam Provincial Government. Health impact investigation in areas with industrial contamination. Hongseong: Chungnam Provincial Government; 2016, p. 45-80 (Korean).

12. Lim JA, Kwon HJ, Kim S, Chou Y, Gu S, Jeong HS, et al. Process and results of Seoul Metropolitan Government's environmental health policy road map. J Environ Health Sci 2014;40(5):425-434 (Korean).

13. Gyeonggi Research Institute. Strategy to achieve Atopy Free Gyeonggi-do. Suwon: Gyeonggi Research Institute; 2012, p. 1-5 (Korean). 